\title{
Inner Speech: Nature and Functions
}

\author{
Agustin Vicente* and Fernando Martinez Manrique \\ Ikerbasque (University of the Basque Country) and University of Granada
}

\section{Abstract}

We very often discover ourselves engaged in inner speech. It seems that this kind of silent, private, speech fulfils some role in our cognition, most probably related to conscious thinking. Yet, the study of inner speech has been neglected by philosophy and psychology alike for many years. However, things seem to have changed in the last two decades. Here we review some of the most influential accounts about the phenomenology and the functions of inner speech, as well as the methodological problems that affect its study.

\section{Introduction and Historical Overview}

We spend a good amount of our conscious life doing something that looks like talking to ourselves. Even when we dream we seem to be engaged at times in this inner talk. Giving an account of this phenomenon would cast light on the relation between language and consciousness. However, the nature and function of inner speech are far from clear. Here we will try to shed some light on this phenomenon by critically surveying what contemporary philosophers and psychologists have recently said about the issue.

It must be kept in mind that inner speech is not to be confused with the language of thought (LOT). According to the LOT hypothesis (Fodor 1975), thought is carried out in a representational format that constitutes a language. Yet, this language is not a public language: indeed, most of the defenders of the LOT hypothesis regard it as different from natural language in the sense of having its own combinatorial syntax and compositional semantics. Inner speech, on the other hand, is closely related to one natural language spoken by a person - typically her first language, but it could also be a second language. As we will see later, it is also a matter of debate whether the vehicle of inner speech is a subset from a natural language, or something that has its own syntactic and semantic peculiarities.

\section{Methodological Issues: How to Know Something About Inner Speech}

As other consciousness-related phenomena, inner speech is not easy to investigate, and its study raises a number of issues on the methodology of science. Investigation of inner speech is part of investigation of auditory imagery in general, where an important problem is, as Hubbard (2010) contends, how to provide convincing evidence that such imagery was actually generated, evoked, or used. With that caveat in mind, Hubbard surveys empirical findings from data that include subjective reports, comparison of performances with and without auditory imagery, brain imaging studies, and clinical data regarding pathologies of auditory imagery. Focusing more specifically in methodology, Guerrero (2005, ch. 4) provides a comprehensive review of methods that are available to conduct research on inner speech: the genetic method, verbal reports, and laboratory tools. 


\section{Inner Speech}

The genetic method draws on the Vygotskyan tradition of distinguishing between inner and private speech (Wertsch 1985; Frawley 1997). Private speech is audible speech directed to oneself, and it can be typically observed in young children, who guide their own behaviour this way. The assumption is that private speech is the precursor of inner speech, so that studying the former opens a way into the latter. Private speech can also be observed in adults, and the assumption in this case is that it is externalized inner speech. The main advantage of this method is the greater objectivity of the observations of overt speech, while its main problem lies precisely in what it takes for granted, namely, that private speech is indeed a precursor or an externalization of inner speech and that they are structurally and functionally similar. So it is unclear whether one is actually studying the same kind of phenomenon.

Verbal reports are based on subjective reports from the individuals' own experiences of inner speech. They can be either retrospective reports, such as questionnaires or interviews, or more introspective, 'on-line' verbalization, such as think-aloud protocols. A particularly interesting method is randomly sampling thinking (Hurlburt 1997), which tries to capture people's reports of their real-life conscious experiences at a short lapse after they take place. This way it is possible to collect quantitative data about the relative frequencies of different kinds of experience, and to compare different groups of individuals. The advantage of these methods is that they provide a path to the phenomenon as it appears to people themselves. The main disadvantage comes from the fact that people may have limitations on what they are able to report, and they may require specific training to do so, which subsequently can affect the reliability and independence of the report. Hurlburt and Schwitzgebel (2007) provides a rich debate concerning the reliability of such introspective methodology.

Laboratory tools involve different recording methods for an array of physiological events related to covert language production. An advantage is that it is possible to obtain more precise measurements and correlations with other data, while disadvantages lie in the lack of ecological validity, and the fact that is that it is not clear what mental phenomenon is correlated with each respective record. For instance, it may be very difficult to disentangle those physiological events related to inner speech per se, as opposed to events that are implicated in language processing in general, be it conscious or not. It must be noted that inner speech draws on mental mechanisms devoted to language production but linguistic processors are involved in many other tasks, most of them carried at the unconscious level. So it may not be easy to tell apart the distinctive functional role of inner speech, as opposed to the role of the language system itself.

\section{The Phenomenology of Inner Speech}

The nature of inner speech may be studied by purely psycholinguistic means, in terms of the representational constraints the theories need to posit so as to account for the empirical findings, as represented by MacKay (1992). Yet a preliminary problem is that any theory seems to rely, one way or another, on phenomenological data provided by participant experimental tasks. This raises the question of the phenomenological nature of inner speech. Partly due to the mentioned methodological difficulties, and surely due to the generalized disinterest in phenomenology of XXth century psychology, there is still a lack of phenomenological data about inner speech, as several authors have pointed out. For instance, Jackendoff (2007: 80) complains that there is little phenomenal description in the cognitive neuroscience of consciousness, and that most of it is devoted to visual experience, while Zlatev (2008: 7) remarks that even in the new 
'phenomenological turn' in cognitive science (e.g., Gallagher and Zahavi 2008) there is surprisingly little said about language. This lacuna is all the more surprising, given the amount of time our minds are engaged in inner talk. Some studies show (e.g., Heavey and Hurlburt 2008) that compared with other conscious experiences, such as images or feelings, inner speech takes an average of $26 \%$ of our conscious waking life, although it can vary widely from subject to subject. Other studies raise this rate to $75 \%$ or higher (Klinger and Cox, 1987-88).

It is customary to take inner speech to be a phenomenologically and syntactically impoverished form of our own talking, which is also semantically idiosyncratic. In this view, inner speech not only lacks pitch and volume and even certain forms of prosody but also appears typically in subsentential linguistic items, sometimes even so austere as 'ah', 'yes', 'not this way', 'where the hell?' and 'the meeting!' (see Peacocke 2007). The meaning of those linguistic items seems to be clear to us but they might be to a large extent unintelligible to others if we uttered them. In fact, even if impoverished with respect to articulatory properties, inner speech seems to be in contact with lexical and other high-level information involved in semantic comprehension (Oppenheim and Dell 2008). However, people can also engage in a more 'sophisticated' inner talk, seemingly carried out in full sentences. This is especially noteworthy in cases such as when we prepare a lecture, think hard about an argument, or imagine possible conversations. Those cases are typically related to linguistic actions, i.e., what our inner speech is doing can be characterized as a sort of rehearsal of the utterances that the subject will eventually make public. However, sophisticated inner speech may also take place in other kinds of situations. For instance, in a research comparing the phenomenological qualities of inner speech in voice-hearing schizophrenia patients and healthy controls, Langdon et al. (2009) found that both groups were most likely to report thinking in full sentences when engaged in inner speech. This result is somewhat surprising, for it has been typically assumed, following Vygotsky, that one of the typical features of inner speech is its being habitually abbreviated (or fragmentary).

Langdon et al.'s research, on the other hand, reveals that the phenomenology of inner speech is different from auditory verbal hallucinations, so that people that suffer from the latter are able to distinguish those episodes from instances of inner speech, and the phenomenological qualities of their hallucinations do not relate to corresponding qualities of inner speech, viz., hallucinations resemble voices. Besides, 'alien voices' seem to differ from inner speech in terms of their overall form and their pragmatic features (as, for instance, the kind of pronouns they use to address the subject). Other groups in which differences in inner speech could be expected are individuals with Autism Spectrum Disorder (ASD), and deaf people. The fact that people with ASD have defective social interaction and a number of language-related impairments, together with the assumption that outer interpersonal speech is the precursor of inner intrapersonal talk, suggests that the latter may be equally impaired in autism. However, the question is still controversial, with some studies showing that autistic individuals do not use inner speech to the same extent as normally developing children in a number of tasks (Whitehouse et al. 2006; Wallace et al. 2009), and others supporting the conclusion that both kinds of groups use inner speech to the same extent when they are matched in mental age (Williams et al. 2008).

Deafness, on the other hand, offers apparently a case in which striking phenomenological disparities can be anticipated. Indeed, it seems that deaf individuals engage in an analogue of inner speech yet they recruit different mechanisms for it, namely, mechanisms involved in the internal visualization of signs (Sacks 1989). However, if one includes 
form, rather than associated sensory mode, as a relevant phenomenological property, then the differences diminish given that one ought to include syntactic aspects as well. In addition, there is evidence that 'inner signing' is mediated by similar regions to inner speech, namely, the left inferior frontal cortex (McGuire et al. 1997).

\section{The Functions of Inner Speech}

\section{I. THE COMMUNICATIVE VS. THE COGNITIVE ROLE OF LANGUAGE}

As this short presentation makes clear, there are still many lacunae in the study of the nature of inner speech. It is possible to find more interesting developments in the functions of inner speech, even though this is also quite a recent object of study. Among the authors who have addressed this issue recently, Carruthers (1996) distinguished between two broad functions of language: the communicative and the cognitive function. The dominant tradition in the cognitive sciences regarded language as just a means to communicate or express our thoughts, which is yet another reason why the study of inner speech has been obviated. Yet, in addition language could have a role to play in a number of cognitive processes, either as an aid or even as the primary means by which the process is realized. However, the assumption that language has a cognitive function can be qualified in a number of ways.

First, it must be noticed that talking about functions of language does not immediately extend to inner speech, as the functions of language could be unrelated to our phenomenological experience of talking to ourselves. Yet the sheer fact that we experience this sort of activity calls for explanation: why should we engage in self-talk at all? Baars (1988, 2001), Dennett (1991), or Carruthers $(2002$, 2006) provide an answer from the assumption that communication between different parts of the mind is suboptimal. Consciousness would offer a means to integrate information (more on this later), and the conscious products of the language system - i.e., inner speech - would play a crucial role in this respect. So in Baars's global workspace theory inner speech would be one of the conscious elements on which working memory depends, in Dennett's multiple drafts theory it would be part of the Joycean machine that runs on the mind's basic machinery, and in Carruthers's massively modular architecture it appears as a global broadcaster of thoughts.

Second, the idea that inner speech has a cognitive function to play comes in milder or stronger forms. So the roles attributed to inner speech range from the strong view of regarding conscious language as the vehicle of (at least some sorts of) conscious thoughts to weaker views that posit different cognitive functions for inner speech. Broadly construed, such functions involve thought broadcasting, behaviour control, or the construction of the self. Attending to more specific types of cognitive tasks, inner speech seems to play a significant role in tasks that allows for verbal self-regulation, such as reasoning, planning, memory, or attribution of mental states.

Third, the claim that inner speech has functions to play other than communication does not necessarily mean that it was selected for those functions. So Pinker and Jackendoff (2005) hold that the adaptive function of language is social communication while other functions exploit the language's properties in a derivative way. Indeed it is also questionable whether the cognitive roles of inner speech mark a distinctive function for it, i.e., something that without inner speech could not be performed as efficiently, or even not performed at all. As Fields (2002) points out, many of the cognitive functions that inner talk seems to play could be equally played by outer talk - indeed, some of those 
functions could be better served by outer talk. The fact that we normally rely on inner speech for them could be due to other reasons, such as the pressure to hide our thoughts from others, or even as a non-necessarily adaptive by-product of our cognitive architecture - something that we can't help doing even if it is not the optimal way.

Finally, it can even be questioned whether inner speech is actually functional, in the sense of having typically beneficial consequences. Actually, it is not always the case that cognitive tasks, even cognitive tasks that involve attention, are improved by the use of inner speech. Sometimes quite the reverse is true, as shown in the phenomenon of verbal overshadowing (Memon and Meissner 2002; Chin and Schooler 2008). For instance, in a classical experimental setting all subjects watched a video about a certain salient individual that they would have to identify afterwards. After watching the film and before testing their identification capacity, some subjects had to describe verbally the target individual while others had to read an unrelated text for the same amount of time. The results showed that the subsequent performance in recognizing the individual (e.g., picking $\mathrm{him} /$ her out of a line-up) was poorer for those subjects that had been asked to describe the individual. This phenomenon is robust in the domain of face recognition - where it was originally demonstrated - but it has been apparently observed in domains such as decision making, problem solving, analogical reasoning, or visual imagery. At any rate, it seems that both the beneficial or disruptive properties of inner speech can be regarded as a consequence of how it functions in the global mental capacities, and it is to this issue that we turn our attention.

\subsection{THE PHONOLOGICAL LOOP, BEHAVIOUR CONTROL, AND SECOND-ORDER DYNAMICS}

In the classical model of working memory (Baddeley 1986) inner speech is due to the function of the phonological loop system. This is a component specialized in short-term storage of verbal (phonological) information. When the phonological loop involves articulatory rehearsal, inner speech would be produced as a form of subvocalization. This loop plays a role in memory by allowing information kept in working memory to be further processed and eventually committed to long-term memory. The system seems to have a relevant role to play in monitoring speech production. The idea is that people are able to inspect something like a 'plan' of their phonetic output that can be compared to ongoing overt speech so as to correct slips of the tongue when a mismatch is detected. There are discrepancies, however, about how inner speech is monitored (see Hartsuiker and Kolk 2001; Huettig and Hartsuiker 2010). One theory, stemming from Levelt (1983), is that monitoring is carried out by the same mechanisms involved in speech perception, while alternative views hold that internal monitoring is directed towards speech production, not perception.

This function of the phonological loop seems to be limited to language-internal duties, either to enhance verbal memory or to aid successful linguistic production. However, it may have a larger role to play in cognitive control. For instance, the supporting role of inner speech in executive control of behaviour has been explored in the context of facilitating switching from one task to a different one (Emerson and Miyake 2003), and in artificial models of 're-entrant' speech for self-regulation of behaviour (Clowes 2007).

The emphasis on control shows a broad Vygotskyan influence that can be ascertained in many contemporary theorists. In Vygotsky's view (Vygotsky 1934), language is first and foremost an external tool that not only serves to communicate thoughts but also to gain increasing control over one's actions. A child typically relies first on external instructions and clues that guide her actions, then the process takes the form of an outer 
monologue, and later on the monologue is internalized. With time, it acquires the typical form of inner speech.

Many authors coincide with Vygotsky in ascribing to inner speech the function of giving control over our actions by bringing relevant information to our attention. However the point is also often put in terms of consciousness. The claim is that the function of inner speech is to enable us to engage in conscious thinking, or to be conscious of our own cognitive processes. The functions of inner speech, thus, overlap with the functions of conscious thinking: inner speech allows us to have controlled and serial behaviour, retrieve and consolidate memories more easily and, in general, facilitate certain otherwise demanding cognitive processes. For instance, Clark (1998) claims that language is an external tool for control that we interiorize. By so doing, we can 'objectify and contemplate our own thoughts'. Converting thoughts in objects by formulating them linguistically enables us to hold the focus on our thinking, which in turn enables us to have a better control of our behaviour, of our planning and of our cognitive processing in general. In Clark's words, language enables us to enter into a 'second-order dynamics'. But the idea here is not that language allows us to have second-order thoughts; rather, the idea is that language allows us to make thoughts conscious.

For instance, it is in this respect that inner speech seems to play a pivotal role in a philosophically significant aspect of mental such as self-awareness. So Morin $(2005,2008)$ proposes that one becomes self-aware when one engages in self-talk about one's current mental states and personal characteristics. There are several ways in which inner speech provides information about the self. One is by reproducing information provided by external systems, e.g., replicating overt conversations with others. Another is by describing verbally information that is acquired by other means (e.g., visual) - allowing thus a better integration with other self-related pieces of information. Yet another one is to produce a sort of 'distance' within the self, which is necessary for self-observation. 'Objectifying thought' in speech would be a means to fulfil these roles.

\subsection{THE VEHICLE OF CONSCIOUS THOUGHT}

Perhaps the idea that has attracted more philosophical work on inner speech is a strong reading of this general thesis that inner speech is used to make thoughts conscious or enter into a 'second-order dynamics'. Hence it is useful to pay a closer attention to authors that have recently defended variants of this reading, such as Carruthers, Bermúdez, Jackendoff and Prinz. For instance, Carruthers (1996) claimed that we use natural language as a vehicle of some of our thoughts. His claim was that some thoughts that we have are literally the content of sentences of a natural language. He takes introspection as a starting point assuming that it reveals that sometimes people think in a natural language, and arguing that we must take these data from introspection for what they seem.

Bermúdez (2003) also endorses the view that inner speech carries conscious thoughts. He follows Clark's suggestion that language provides a second-order dynamics, which he equates with reflexive thinking. This is the kind of thinking involved in abilities such as proper reasoning, revision and ascription of beliefs, having embedded compound thoughts, and having intermodular thoughts (more on this later). The idea is that we cannot engage in reflexive thinking unless we use language because the only way to have thoughts as the object of further thoughts is by having them encoded (formulated) in some vehicle that is propositional and introspectable. The language of thought, which is a vehicle of propositional thinking, is not introspectable, so it cannot be the basis of reflexive thinking. According to him, the only vehicles that fulfil both conditions are natural 
language sentences. As in the case of Carruthers, the claim is based on introspection, given that the propositional thoughts that we consciously introspect appear as sentences in a public language.

Jackendoff (1996) and Prinz (2007) endorse a non-Vygotskyan position that is known as the 'intermediate-level theory of consciousness'. Jackendoff's point is that our conscious perception is intimately linked to the particular perspective in which we engage the object, and that this perspective is provided by a representational level that is intermediate between a representation of local stimulus features, and a conceptual representation. We are incapable of being aware of our own thoughts as such. The only way we have of being conscious of what we think is by generating phonological representations, i.e., intermediate-level linguistic representations that correspond to, and behave as surrogates for, such thoughts. People can have experience of abstract thoughts and chains of reasoning only by means of this linguistic modality.

Prinz provides an update of Jackendoff's intermediate level view, claiming that all consciousness is perceptual. Thus, the only way to be conscious of a thought is by entertaining it in some perceptual modality. A consequence of this view, apparently unnoticed by Prinz himself, is that the only perceptual modality that can possibly make propositional thoughts conscious is the linguistic modality, given that images are typically non-propositional.

There are two basic problems with all these proposals, or with any other proposal that ends up claiming that inner speech encodes conscious thoughts. The first problem is that they can account for only part of the phenomenological data: These theories can explain what's going on when we are entertaining complete sentences at the conscious level. However, first, they are in trouble to tell us what we are doing when our inner speech takes a more condensed or fragmentary form. A subsentential utterance does not encode a proposition, or, in other words, it does not carry a complete thought-content. So, if the use of language in thought is essentially related to language's being a propositional format, the role of fragmentary inner speech is unclear (see also Hurlburt and Schwitzgebel 2007). The second sort of data that is problematic for these theories is the one related to unsymbolized thinking. According to Hurlburt and colleagues (see Hurlburt and Akhter 2008) individuals frequently report having thoughts without the experience of speech, images, or other symbols.

The second problem is the following: The present accounts assume that language can be a vehicle of propositional thought insofar as sentences can carry propositional content. However, this assumption has been challenged in the current debate between minimalism and contextualism in philosophy of language and pragmatics (see, e.g., Carston 2002; Borg 2004; Recanati 2004). Contextualists have offered a plethora of evidence that undermines the thesis that sentential utterances can carry propositions by themselves, i.e., as a matter of pure semantics. This means that, no matter whether we experience 'full' sentences or only fragments of them, the thoughts we are bringing to mind have more content than the content carried by the linguistic items we introspect (see Vicente and Martínez Manrique 2005). This claim has devastating consequences for the theories presented in this section. To mention just two of these consequences: Firstly, Bermúdez's argument that only linguistic individuals can engage in reflexive thought, hinges crucially on language's being the only propositional format. However, if language is not such a propositional format, it follows that reflexive thinking is possible in the absence of language. Secondly, Jackendoff and Prinz claim that all consciousness is perceptual. Yet, if language brings thoughts to consciousness, and thoughts are not encoded by linguistic sentences, we have to be conscious of something that is not perceptually encoded. So, not all consciousness would be perceptual. 


\subsection{INTERMODULAR INTEGRATION AND GLOBAL BROADCASTING}

As it has been noted, Bermúdez claims that one of the cognitive functions of language is 'intermodular integration'. This is an idea championed by Spelke (2003) and Carruthers (2002, 2006). Here we will focus on Carruthers's (2006) account, as Spelke's approach seems to be neutral as to whether this function is subserved only by language, with inner speech having no further role to play in it.

Carruthers's (2006) new position no longer regards language as a vehicle of conscious thinking, but as a tool for it - as we saw, a position also endorsed by Clark (1998). Carruthers's current concerns about language arise from his commitment to a massively modular architecture of mind, where minds are composed by a myriad of distinct processing systems, each performing some specific task in the functioning of the whole. One of the problems of this architecture is to explain human cognitive flexibility as well as human creativity.

Carruthers argues that language plays a prominent role in the explanation of both flexibility and creativity. Language is an input-output system that provides the means to integrate information coming from different domain-specific modules. The recursive syntactic character of language provides the resources to this end. However, this seems to be a task for the linguistic processors, and not for inner speech itself. A specific task for inner speech comes when the integrated information is subsequently broadcasted and made accessible both to consciousness and to the different central modules (see also Baars 1988). This way language can make thoughts available to conscious thinking in a massively modular mind.

Roughly speaking, our conscious inner talk consists in the generation of phonological images of linguistic actions that are aborted before they produce actual speech. Now, there are two basic problems with this general account. The first is that, as modules are typically domain-specific, there seems to be no central module capable of 'understanding' the information the linguistic module is allegedly integrating and broadcasting (see Machery 2008). The second problem is that Carruthers draws a parallel between animal thinking, enabled by the rehearsal of action-schemata, and human thinking, enabled mostly by the rehearsal of linguistic action schemata. However, this is only a part of what we do with inner talk, i.e., our inner speech serves more functions than broadcasting possible courses of linguistic actions. More often than not, what we tell ourselves is not anything we would be going to tell anybody. Rather, it seems that we have to quasi-speak just in order to know what we think, and thus control our subsequent actions, but 'quasi-speech' is not 'possible outer speech', as animals' quasi-actions are possible actions.

\section{Conclusion}

We find that the debate about the nature and functions of inner speech is a fascinating and important one, if only because of the importance that inner speech seems to have in our mental lives. Yet, we dare to say that the debate is only in its inception at the present stage. Most authors endorse a minimal Vygotskyan thesis about inner speech, namely, that it is basically an instrument for controlled behaviour. Their different views can be seen as different ways to flesh out, and in some cases, go beyond, this minimal thesis, but the proposals are still very speculative. Many of these authors also endorse a second Vygotskyan thesis, namely, that inner speech is a peculiar form of speech (specially condensed and perhaps semantically idiosyncratic).

We think that these two minimal Vygotskyan theses are on the right track and that they should be the starting points of future research. In our view (Martínez-Manrique 
and Vicente 2010), what they suggest is that what we recruit in inner speech is not so much language as a system of structure and symbols, but as a means of communication. That is, we internalize the best way we have to communicate our thoughts to others in order to communicate them to ourselves, which results in them being conscious. However, just as we can make someone conscious of our thoughts by using a subsentential utterance, we can bring our own thoughts to consciousness by using a very fragmentary form of speech (given that we can rely on the contextual background maximally). In this way we can engage in all those forms of conscious cognition that we have been speaking about through the paper.

However, in order to evaluate this and all the other proposals we have to know more about the nature both of inner speech and of conscious thinking. For instance, we need to know whether, in effect, inner speech takes the form of a fragmentary speech, and, if so, how often it takes that form. We also need to know how the production of inner speech correlates with controlled behaviour, and whether and how this correlation differs when we contrast condensed with expanded inner speech. Finally, in order to know whether the role of inner speech in conscious thinking is essential or not, we need data from aphasias. Yet, to our knowledge, there is at present a lack of data here. Some authors like Damasio (1999) claim that even global aphasics have a spared capacity for conscious thinking. However, he doesn't provide any evidence for this claim.

\section{Acknowledgement}

This paper was written within Research Project FFI2008-06421-C02-01\&2 from the Spanish MICINN. The authors wish to thank an anonymous referee for his/her valuable comments. This article is thoroughly collaborative. Order of authorship is arbitrary.

\section{Short Biographies}

Agustín Vicente is Research Professor at the Ikerbasque Foundation for Science/University of the Basque Country, and Fernando Martínez-Manrique is Professor of Philosophy at the University of Granada, Spain. Their common areas of interest are primarily philosophical issues on mind, language, and psychology. Together or independently, they have published on these topics in journals such as British Journal for the Philosophy of Science, Dialectica, Journal of Consciousness Studies, Mind and Language, Minds and Machines, Philosophical Studies or Pragmatics and Cognition.

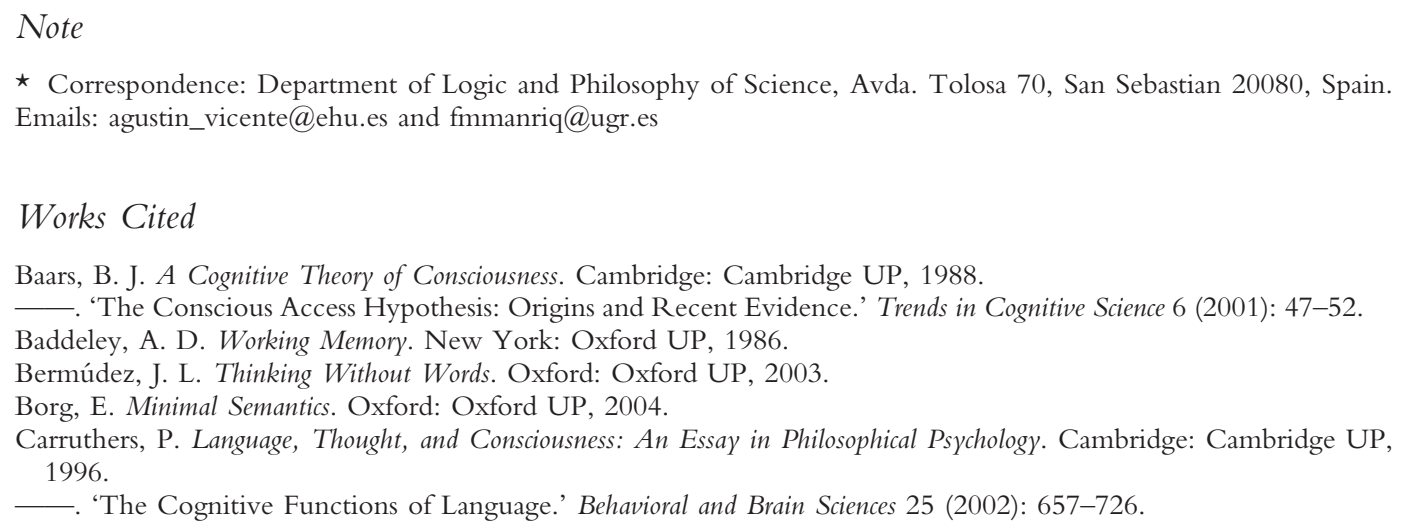


The Architecture of Mind. Oxford: Oxford UP, 2006.

Carston, R. Thoughts and Utterances. London: Blackwell, 2002.

Chin, J. M. and J. W. Schooler. 'Why do Words Hurt? Content, Process, and Criterion Shift Accounts of Verbal Overshadowing.' European Journal of Cognitive Psychology 20 (2008): 396-413.

Clark, A. 'Magic Words: How Language Augments Human Computation.' Language and Thought: Interdisciplinary Themes. Ed. P. Carruthers, J. Boucher. Cambridge: Cambridge UP, 1998. 162-83.

Clowes, R. 'A Self-Regulation Model of Inner Speech and Its Role in the Organisation Of Human Conscious Experience.' Journal of Consciousness Studies 14 (2007): 59-71.

Damasio, A. The Feeling of What Happens: Body and Emotion in the Making of Consciousness. San Diego, CA: Harcourt, 1999.

Dennett, D. C. Consciousness Explained. New York: Little, Brown and Company, 1991.

Emerson, M. J. and A. Miyake. 'The Role of Inner Speech in Task Switching: A Dual-Task Investigation.' Journal of Memory and Language 48 (2003): 148-68.

Fernyhough, C. 'Alien Voices and Inner Dialogue: Towards A Developmental Account of Auditory Verbal Hallucinations.' New Ideas in Psychology 22 (2004): 49-68.

Fields, C. 'Why Do We Talk To Ourselves?' Journal of Experimental and Theoretical Artificial Intelligence 14 (2002): $255-72$.

Fodor, J. The Language of Thought. Cambridge, MA: Harvard UP, 1975.

Frawley, W. Vygotsky and Cognitive Science. Cambridge, MA: Harvard UP, 1997.

Gallagher, S. and D. Zahavi. The Phenomenological Mind: An Introduction to Philosophy of Mind and Cognitive Science. London: Routledge, 2008.

de Guerrero, M. C. M. Inner Speech - L2: Thinking Words in a Second Language. New York: Springer, 2005.

Hartsuiker, R. J. and H. H. J. Kolk. 'Error Monitoring in Speech Production: A Computational Test of the Perceptual Loop Theory.' Cognitive Psychology 42 (2001): 113-57.

Heavey, C. L. and R. T. Hurlburt. 'The Phenomena of Inner Experience.' Consciousness and Cognition 17 (2008): $798-810$.

Hubbard, T. L. 'Auditory Imagery: Empirical Findings.' Psychological Bulletin 136 (2010): 302-29.

Huettig, F. and R. J. Hartsuiker. 'Listening To Yourself Is Like Listening To Others: External, But Not Internal, Verbal Self-Monitoring Is Based On Speech Perception.' Language and Cognitive Processes 25 (2010): $347-74$.

Hurlburt, R. T. 'Randomly Sampling Thinking in the Natural Environment.' Journal of Consulting and Clinical Psychology 65 (1997): 941-9.

— and S. A. Akhter. 'Unsymbolized Thinking.' Consciousness and Cognition 17 (2008): 1364-74.

— and E. Schwitzgebel. Describing Inner Experience? Proponent Meets Skeptic. Cambridge, MA: MIT Press, 2007.

Jackendoff, R. Consciousness and the Computational Mind. Cambridge, MA: MIT Press, 1987.

- 'How Language Helps Us Think.' Pragmatics and Cognition 4 (1996): 1-35.

- Language, Consciousness, Culture: Essays on Mental Structure. Cambridge, MA: MIT Press, 2007.

Klinger, E. and W. M. Cox. 'Dimensions of Thought Flow in Everyday Life.' Imagination, Cognition and Personality 7 (1987-1988): 105-28.

Langdon, R., et al. 'The Phenomenology of Inner Speech: Comparison of Schizophrenia Patients With Auditory Verbal Hallucinations And Healthy Controls.' Psychological Medicine 39 (2009): 655-63.

Levelt, W. J. M. 'Monitoring and Self-Repair in Speech.' Cognition 14 (1983): 41-104.

Machery, E. 'Modularity and the Flexibility of Human Cognition.' Mind E Language 23 (2008): $263-72$.

MacKay, D. G. 'Constraints on Theories of Inner Speech.' Auditory Imagery. Ed. D. Reisberg. Hillsdale, NJ: Erlbaum, 1992. 121-49.

Martínez-Manrique, F. and A. Vicente. 'What the...! The Role of Inner Speech in Conscious Thought.' Journal of Consciousness Studies 17 (2010): 141-67.

McGuire, P. K., et al. 'Neural Correlates of Thinking in Sign Language.' NeuroReport 8 (1997): 695-8.

Memon, A. and C. A. Meissner. 'Special Issue: Investigations of the Effects of Verbalization on Memory.' Applied Cognitive Psychology 16 (2002), 869-997.

Morin, A. 'Possible Links Between Self-Awareness And Inner Speech: Theoretical Background, Underlying Mechanisms, And Empirical Evidence.' Journal of Consciousness Studies 12 (2005): 115-34.

- 'Self-Awareness Deficits Following Loss of Inner Speech: Dr. Jill Bolte Taylor's Case Study.' Consciousness and Cognition 18 (2008): 524-9.

Oppenheim, G. M. and G. S. Dell. 'Inner Speech Slips Exhibit Lexical Bias, But Not the Phonemic Similarity Effect.' Cognition 106 (2008): 528-37.

Peacocke, C. 'Mental Action and Self-Awareness.' Contemporary Debates in the Philosophy of Mind. Ed. J. Cohen, B. McLaughlin. Oxford: Blackwell, 2007. 358-76.

Pinker, S. and R. Jackendoff. 'The Faculty of Language: What's Special About It?' Cognition 95 (2005): $201-36$.

Prinz, J. 'All Consciousness Is Perceptual.' Contemporary Debates in the Philosophy of Mind. Ed. J. Cohen, B. McLaughlin. Oxford: Blackwell, 2007. 335-57.

Recanati, F. Literal Meaning. Cambridge: Cambridge UP, 2004.

Sacks, O. Seeing Voices. Los Angeles: University of California Press, 1989. 
Spelke, E. S. 'What Makes Us Smart? Core Knowledge and Natural Language.' Language in Mind. Ed. D. Gentner, S. Goldin-Meadow. Cambridge, MA: MIT Press, 2003. 277-311.

Vicente, A. and F. Martínez Manrique. 'Semantic Underdetermination and the Cognitive Uses of Language.' Mind and Language 20 (2005): 537-58.

Vygotsky, L. S. Myshlenie i rech': Psykhologicheskie issledovaniya. Moscow and Leningrad: Gosudarstvennoe Sotsialno-Ekonomicheskoe Izdatel'stvo, 1934. (Thought and Language. Cambridge, MA: MIT Press, 1962).

Wallace, G. L., et al. 'Further Evidence for Inner Speech Deficits In Autism Spectrum Disorders.' Journal of Autism and Developmental Disorders 39 (2009): 1735-9.

Wertsch, J. V. Vyootsky and the Social Formation of Mind. Cambridge, MA: Harvard UP, 1985.

Whitehouse, A. J. O., M. T. Maybery and K. Durkin. 'Inner Speech Impairments in Autism.' Journal of Child Psychology and Psychiatry 47 (2006): 857-65.

Williams, D., F. Happé and C. Jarrold. 'Intact Inner Speech Use in Autism Spectrum Disorder.' Journal of Child Psychology and Psychiatry 49 (2008): 51-8.

Zlatev, J. 'The Dialectics of Consciousness and Language.' Journal of Consciousness Studies 15 (2008): 5-14. 